\title{
Major Turns in Planned Development of Nepal
}

\author{
Nagendra Lal Srivastava
}

\begin{abstract}
Three major turns in the pattern of development plans have been clearly realized. First has been seen in fifth plan in which the concept of regional de velopment was introduced along with strengthening of party less Panchayat system. The Second turn has been found in eighth plan that was the first plan after the restoration of multi party system in 1990. The change in this plan was seen in the form of guaranteeing democratic rights and opportunities to the people in existing socio economic and political scenario along with the promotion of privatization and economic liberalization. The third turn has been reflected in the current interim plan. The change has been seen through the aspirations of people that have been incorporated here in various ways to make a new Nepal. All the turns have been identified through the difference in plan objectives, policies and strategies that have been affected by influential change in socio political situations of the country due to some epoch making events.
\end{abstract}

Key words : Major turns, planned development

\section{Introduction}

This article basically aims to see whether all development plans in Nepal follow the same pattern or not. The difference in plan pattern has been identified with the help of difference in objectives, strategies and policies along with the existence of socio political and economic situation in which the plan was prepared. The whole article has been divided in three parts, e. g. introduction, analysis of turns in development plans and conclusion.

Just after few years after the downfall of Rana Rule, the then government made an stride in the direction of improving the wellbeing of people by starting the first development plan in 1956. It is the first turning point in economic development of Nepal because the plan had envisaged creating a socio economic environment so that people of Nepal could also live a happy and prestigious life. During Rana regime, most of country resources were utilized for the pleasure and prosperity of few Rana rulers and their relatives. The plan was not successful as thought. The main reason of the unsuccessfulness was given to the lack of basic infrastructure, i. e. information about the economy for formulating an efficient plan. Hence the second plan was not started just after the end of first plan. The second plan 
started one year late. Thus there was a planning holiday of one year. This holiday was used in preparing the basis of planned development. However, it was successful in the way that it had opened a door of planned development in Nepal and had tried to divert the resources for uplifting the life of mass.

\section{Turns in development plans}

So far since the commencement of first plan in 1956, Nepal has completed ten plans till 2006 in a long period of almost of fifty years. All are of five year plans except the second one that was of only three years extending from 1962 to 1965 . First seven plans were completed by Panchayat system. Multi party system under the kingship had completed eighth, ninth and tenth plans. This is the final year of ongoing three year interim plan that has been started after the downfall of Kingship because of historical people's movement in 2006. In the whole period of planned development, all plans have not been found of the same pattern because of the changing socio political condition and demand of time regarding the switch in economic policies. So far, three major turns have been found in the total period of almost half century of development plans in Nepal that have been mentioned below.

\section{Fifth Five Year Plan}

The over all patterns of plans up to fourth development plan regarding setting and nature of objectives, formulating strategies and policies, allocating expenditures and exploring the sources of finance are found almost the same. For the first time, a change was introduced in the pattern of fifth plan. Hence one can take fifth plan as the first major turn in the process of planned development in Nepal. The purpose of this type of turn (change) was realized to make the plan some more realistic, people oriented, practical, regional and effective (NPC, 2032: preface). Earlier plans had been found of lagging these aspects. The objectives and policies of fifth plan mentioned below make this matter more clear (Ibid: 22-27).

\section{Objectives of fifth plan}

Since this plan had been thought to be prepared in different pattern to that of other previous plans, its objectives were some more comprehensive as given below.

\section{Increase in the production of peoples' requirements}

The objective was not to maximize the national production. Rather, it was thought to maximize the production of those goods and services which could meet the daily requirements of mass. 


\section{Maximum utilization of labor power}

Nepal is a country of low capital. Besides, many people are unemployed in one or other way. It was thought to have the maximum use of labor force by increasing the investment, especially in non agricultural sector and emphasizing the labor intensive technology.

\section{Regional balance and unification}

Nepal is a country of diversity in all respects. The resources of the country are also scattered. There has been a big difference in the status of development of various parts of the country. Most parts of the country are almost cut off the efforts of development. The lopsided development could cause a danger in national integrity on the one hand and not proper utilization of scattered resources on the other. So for the first time in the history of development plans, the concept of regional development, specialization and integration were brought in fifth development plan to meet the goal of regional balance in development and strengthening national unity. For this, Nepal was divided in four development regions (eastern, central, western and far western) each having its own headquarters." The scheme was to integrate each region along with Terai, Hills and Mountains by constructing main and sub highways. To have the maximum and better utilization of resources, the concept of regional specialization was also brought for the first time. According to this, Terai, Hills and Mountains were thought to be specialized in agronomy, horticulture and livestock farming respectively as per the availability and suitability of their resources.

\section{Policies of fifth plan}

In order to meet the objectives effectively and efficiently, the plan had selected the following policies.

\section{Mobilization of internal resources}

The government had thought to decrease the dependency on foreign resources by having the policy of increase in public revenue along with improving and developing the efficiency of revenue administration.

\section{Investment production structure}

It was thought that most of the plan expenditure would be incurred by the different

\footnotetext{
- Presently, there are five development regions. The far western development region was divided later in two regions. The new one was named as mid western development region.
} 
levels of Panchayats like, village/ town, district, etc. It was said that Panchayat units would be stronger this way on the one hand and people's participation would increase on the other. Besides, the policy had given the obvious emphasis on the production of people required products.

\section{Labor intensive technology}

It was thought to adapt the labor intensive technology. This would increase the level of employment. Apart from this, this would decrease the need of capital that Nepal lacks.

\section{Economic stability}

The government had thought to have the economic stability with the help of its various tools like monetary and fiscal policies. Otherwise, the fruits of development could not be truly realized.

\section{Industrial arrangement}

The policy was to increase the role of government in the industrial sector. For this, the government would establish various industries under the public sector by mobilizing the internal resources along with the help of foreign grants.

\section{Increase and diversification of foreign trade}

Accepting trade as the engine of growth, the policy selected in the plan was to increase the volume of trade with the practice of its diversification both country wise and product wise.

\section{Land reform}

It was thought to modify the provisions of existing land reform program so that it could guarantee the tenancy right to genuine farmers. The land reform policy would be implemented such a way that it could increase the land and labor productivity. For this, the provision was to make easy supply of inputs like credit, tools, fertilizers, etc for speeding up the process of agricultural modernization.

\section{Role of Panchayat}

The policy was made to increase the role of various tiers of Panchayat system. The idea behind this was to foster the development of farm and rural sector that was dominating in the whole economy of Nepal along with strengthening the party less Panchayat system. 
Sixth and seventh plans, though different in regards of total outlays and priorities, almost followed the same pattern used in fifth plan. Rather, these plans were used to strengthen the fundamentals of Panchayat regime by giving more authorities to different Panchayat units in the name of 'back to village campaign'. However, the new turn in the history of Nepal's planned development taken in fifth plan onward to seventh plan could also not win the peoples' confidence because of their poor achievements and becoming the basis of lopsided development in Nepal.

\section{Eighth Five Year Plan}

After the first people's movement in 1990 that had overthrown the Panchayat regime and restored the multi party system, the eighth plan could not be started at once because any plans formulated at the pattern of previous plans could not meet the aspirations and need of Nepalis. Hence Eighth Plan was started in 1992, two years after the completion of seventh plan. Eighth Plan was to be started at a new pattern with changed vision and strategies so that it could meet the desires of people who had fought for the democracy and multi party system. Eighth plan itself has mentioned the necessity of new pattern in planning by pointing out the fallacies of previous plans. It mentions that during the period prior the restoration of democracy, a three year plan and five year plans were formulated and implemented. Despite the intention of developing the nation rapidly through the utilization of planning as a development tool, the economy could not achieve the desired progress. One of the primary factors for this was the inability to clearly establish interrelationship among goals, objectives, priorities, strategies and programs of the plans. In spite of considerable investment made during the period, no desired progress was achieved. The distortions in policy matters, strategies and programs as well as the weakness in implementation evolved as the characteristic features of the then periodic development planning process. An evaluation of the major economic and physical indicators during this period presents a gloomy picture of the achievements in all previous seven plans. Although during the Panchayat regime progress was made to a certain extent in areas like transportation, communication, health, drinking water, literacy and the ratio of student enrolments, but the economic achievements were vague and disappointing on the whole. No economic changes were brought about in the life style of the majority of population. The economic condition of some segments of population deteriorated even further.

Viewed in the total perspective, in spite of massive investments made in the past, Nepal still remains one of the poorest nations of the world. Although some progress was made in social and physical infrastructural sectors, the progress appeared remarkable only 
in comparison to the negligible figures of the base year. In the absence of any political opposition, there did exist the opportunity of channeling the autocratic character of Panchayat to rapid economic development but, unfortunately, this also did not materialize. The lack of structural change in production hindered the development process from gaining momentum. A low savings rate, the increased share of loan in foreign assistance, low level of industrialization, weak agricultural production, limited export trade and a high population growth rate remained as barriers in the path of development (NPC; 1992: 12-14).

In consequence of the distorted ad hoc economic policies of thirty years interspersed with hollow slogans of disappointing development results and programs without achievements, the country had to bear several economic distortions under panchyat Regime which were as follows (Ibid).

\section{Excessive Control and Regulation}

The control-oriented development approach of the past created many problems. Increased government control, adhoc regulations and procedures, license requirements and other forms of counterproductive bureaucratic behavior tended to discourage decision making process and delays in the disbursement of budgets increased project implementation costs and resulted in the under utilization of the administrative capacity.

\section{Inefficient Public Enterprises}

The performance of state owned enterprises reached a stage of great inefficiency, indifference and apathy. The financial liabilities of these enterprises exceeded the capacity of the government. These enterprises suffered as a result of over staffing, political intervention, inefficiency and the lack of accountability.

\section{Inefficient Investment Portfolio}

Cost-benefit ratios and other criteria which measure the economic and social benefits of projects were neglected in the course of selecting projects to be implemented in various sectors and sub-sectors. The interrelationships among projects and alternative investment options were not taken into consideration. As a result, investment could not be channeled to productive sectors. Many projects were not justifiable from economic and social points of view.

\section{High cost of Economy}

In view of the inaccessibility and the ruggedness of terrain, it was not unusual for the production and delivery costs to be high. But in addition to these realities, the cost component 6 
of the economy had been further aggravated by the dominance of donor driven projects, economically unproductive investments, lack of discipline, limited economic resources of projects, unwarranted expansion of bureaucracy and lack of efficient implementation capabilities.

\section{Inefficient Administration}

Inefficiency in the administration has led to a further deterioration in the government's institutional abilities to effectively implement development programs. The civil service that had been expanding continuously was found under utilized and lacked motivation. Traditional administrative and economic structures, highly centralized authority and the lack of sufficient power at the local levels were some of the reasons of inefficient administration

\section{Faulty Planning Process:}

The planning process remained very weak and was poorly institutionalized. While projects were chosen on an adhoc basis without due consideration to any social or economic criteria, government investments in projects were not based on any long term sustainability considerations. In consequence, there was always a scarcity of resources at the implementation phase. Political decisions were often autocratic and feudalistic. As a result, the planning process lacked accountability and was unable to induce genuine popular participation. Most of the programs became centrally directed in addition to being donor driven.

Because of all this, the Eighth Plan was brought into force in 1992 as a five year plan at a different pattern with new objectives and strategies suitable to the changed local and global context (Ibid: 26-27).

\section{Objectives and strategies of Eighth Plan}

The broad objective of the eighth plan was to give definite direction to the social and economic upliftment of the citizens of the country by tackling the challenges of economic stagnation, increasing poverty, structural anomalies, environmental degradation and rapid population growth. A single five year plan could not find a remedy to all these problems, but it was imperative to take concrete steps in that direction. The plan would make all possible efforts in this regard. The principal objectives that the plan aspired to achieve were as following.

\section{Sustainable Economic Growth}

One of the principal objectives of the plan was to achieve a high and sustainable 
rate of economic growth without which there was no possibility of achieving economic prosperity and its continuity. The economy would not be able to fulfill the developmental aspirations of the common people without a sustainable and high economic growth rate. The eighth plan was determined to achieve a high and sustainable growth rate in the development efforts of the country. Sustainable economic growth also implies the management of the available bio-physical resources in the most productive manner without damaging or depleting these resources. The demand for such biophysical resources should not exceed their sustainable supply capacity. However, the present population of the country is already placing excessive demands on existing resources. If the present trend of population growth is allowed to continue, it will not be possible to meet the demands of the people without causing permanent damage to the bio-physical resources.

Therefore, it was highly essential to reduce the rate of population growth in order to achieve a sustainable economic growth rate. To achieve the above mentioned objective, this plan had called for the involvement of private sector and increased people's participation at the community level. This objective and the concept of equity are complementary to each other. The plan had made additional efforts to increase the productivity of labor force and to make the financial investment more productive. Similarly, programs with higher comparative advantage were to be implemented in agriculture, industry, tourism and other sectors. Comparative advantage could be achieved by the utilization of low cost hydroelectricity and other natural resources in the production process. This would produce a comparative advantage especially in energy -oriented industries and irrigated cultivable land. For this purpose, the advanced technology and institutional reforms would be made indispensable tools of support to the private sector and organizations down to the village level and production would be increased on the basis of equity and capability.

\section{Poverty alleviation}

Despite the development efforts of the past, the population living below the poverty line has been steadily increasing and the majority of such poverty ridden people live in the rural areas. The biggest challenge for the then government was to alleviate poverty from the rural sector. It was the root cause of many of the existing problems of Nepal such as population growth, environmental degradation and social anomalies. Therefore, another principal objective of this plan was to alleviate poverty.

Although poverty is the result of diverse factors, the basic causes of poverty in Nepal are the dependence of the increasing population on limited economic resources and low rate of economic growth. The visible impediments to economic growth such as natural constraints, preliminary stage of development efforts, low productivity, subsistence agricultural system 8 
and slackness in the expansion of non-agricultural sector were found the major factors for a weak economic base. In this perspective, emphasis was given on formulating integrated and interregional programs that primarily focus on the creation of productive assets base and additional employment opportunities to alleviate poverty. Extension of social services like health education, vocational training, drinking water, effective management and protection of natural resources were to be taken as the additional measures of poverty alleviation. Most of the programs would be implemented with the objective of benefiting the population living below the poverty line.

\section{Reduction of Regional Imbalances}

In Nepal, poverty has acquired spatial variations. Despite policy-pronouncements and efforts in the previous plans, disparities between rural and urban areas and among development regions have increased. Over the recent years, there has been an increased trend of migration from rural to urban areas. Hills to Terai migration continue. If the disparity in urban and rural income is not reduced, this trend my gain greater momentum. Similarly, in comparison with other development regions, far western region and mid western region lag far behind in respect of infrastructural and social service facilities and other development works. The living standard of the people of these regions have adversely affected by the growing disparity of income distribution caused by these factors. This has further complicated the creation of equal opportunities for sharing development benefits. In this context, maintenance of regional balance was set as another objective of Eighth plan. While allocating resources in order to achieve regional balance, due attention had been paid to the necessity of creating physical infrastructure in these less developed regions. With this objective, while special emphasis had been given on the extension of rural roads, due importance had been attached to the provision of facilities like primary heath care, education and drinking water in rural sector. The regional complementary interrelationships between Hills and Terai arising out of the existing agro-ecological condition could be beneficially utilized for agricultural and industrial specialization.

Therefore, the current and future development perspectives would be accorded special emphasis in order to benefit from the ecological interrelationships between Hills and Terai. Focusing on the development of less development regions, special emphasis would be laid on the reduction of regional imbalances. In order to achieve the principal objectives mentioned above, it had become essential to improve economic standard of rural people to achieve the self-sustaining rural development through the increased provision of social, economic and market services, and increased access to drinking water and alternative forms of energy. 


\section{Three Year Interim Plan}

Actually, the eighth plan was a five year short term plan as a part of 20 year long term plan that was to cover four five year plans, i.e. eighth, ninth, tenth and eleventh. Hence, ninth and tenth plans were generally formulated at the pattern of eighth plan, though having only single objective of poverty alleviation and some other minor differences.

The eleventh plan could not be started due to change in socio political situation of the country with the downfall of kingship in 2006. As said earlier, the eighth plan could not be started in time. It was started two years later with changed pattern and thinking because of new socio political situation in 1990 that had emerged due to collapse of Panchayat regime. The plan had to incorporate the people's aspirations that they had had to be met in the changed scenario. So, it took a two year time to formulate a development plan of that type. The same situation arose after the end of kingship in 2006 due to people's popular movement. The eleventh plan could not be commenced this time also that should have been continued in the series of development plans just after the completion of tenth plan. The people who had made the movement successful had new aspirations that were to be met to a large extent by the plan. It was very difficult to make a full fledged plan of that type hurriedly. So, an adhoc plan was made of only three years. Thus this three year plan again symbolizes a new turn in the history of development plans. This plan has its own evaluation of previous plans and achievements.

The plan writes that at present, there is a consensus among the political powers in an unprecedented manner. The opportunity emerging after the end of a decade long conflict, enthusiasm, feelings and thoughts raised among the common people is owned as the new energy. This has created a golden opportunity to move forward in raising the living standard of the Nepali people living in poverty, deprivation and backwardness, with strong determination to dismantling old attitudes, obsolete structures and feudal remains. The principal goal of the country now is to take a right turn on development by institutionalizing the historic achievements of the past movements, using such a golden opportunity.

Ten periodic plans have been completed in the five decades of Nepal's efforts on planned development. During this period, development efforts focused on different aspects like the development of physical infrastructure, regional development, fulfillment of basic needs and poverty alleviation. As a result, there has been the construction of huge physical and social development infrastructure and a substantial change in the mutual relationship among the government, civil society and the general people. But the targets of economic growth rates set in the development plans could not be achieved and Nepal lagged behind in economic progress even in relation with the least developed countries. Policies, followed in the past, failed to address the structural problems of the economy like inequitable access to 
productive resources and means, distributional conflict and shortfalls in good governance. Expected improvements could not be realized in the economic and social conditions of women, Dalits, Adibasi Janajati, Madhesis, Muslim community, and the residents of Karnali zone. Such a situation urged conflicts and provided additional energy to it. The People's Movement of Nepal in the past has exposed the existing structural and feudal attitudes in economic, social and cultural areas that have resulted in the form of legacy of classifying the Nepali people in different ways, discrimination based on caste, language, culture and religion, violation of the human rights and the conditions of deprivation in social and geographical terms. These have made the people strong at the same time.

The revolution of 1951 had helped to initiate changes in the system of untouchability, child marriage and the feudal system. Although there appears to be overall positive outcomes and impacts after the People's Movement of 1990 due to the implementation of various programs in line with the changed economic and social policies, disparities have increased instead of decreasing. During this period, the concept of inclusive development could not be comprehensively applied. But the historic struggles of the Nepalese people and the latest movement have directed the country towards a new vision in order to enhance social and economic development with inclusion covering women, Dalits, Adibasi Janajatis, Madhesis, Muslims and the people with disabilities. Because of all this, three year interim plan has been brought forward to have the continuity in development efforts, though completely in a different pattern. (NPC; 2007: 1).

\section{Vision, Goal and Strategy of the Interim Plan}

As said earlier, this plan has been formulated in a different pattern. Instead of directly mentioning the objectives, it has first presented the vision. In other words, the plan has separated the vision, goal and objectives that had not been practiced in previous plans (Ibid: $26-28$ ).

\section{Vision}

With the realization of this envisaged vision, Nepal will be self-sustaining and free from the absolute poverty level. The gap between the rich and the poor will be reduced. The relationship and behavior between the people to people, community and state will improve. All Nepalese will be provided with equal share in legal, economic and social opportunities that will enable them to use their utmost potential. The main vision of this plan is to build a prosperous, modern and just Nepal by having the likely improvement in all conditions of people like social, cultural, educational, economic, political, etc. The plan is supposed to lay down a strong foundation for an improvement in people's behavior, technology and 
innovations that will be absorbed and used. At the same time, all types of discrimination and inequalities like legal, social, cultural, lingual, religious, caste, gender, physical and geographical will be put to an end. There will be a situation where people can experience social justice, basic human rights and good governance. Nepal will be established as a dignified member in the international community.

\section{Goal}

The main goal of this interim plan is to lay a foundation for economic and social transformation to build a prosperous, modern and just Nepal.

\section{Objectives}

The main objective of this plan is to generate an experience of direct feeling of change in the lives of the general public by supporting in the establishment of peace and reducing the existing unemployment, poverty and inequality prevailing in the country.

\section{Strategies}

In order to meet the objectives, the plan has brought forward the following strategies.

\section{To give special emphasis on relief, reconstruction and reintegration}

Priority will be accorded to programs that will help in the reconstruction and reintegration of physical, economic and social infrastructures that were damaged due to conflict. Special emphasis will be given to relief operation and social rehabilitation of individuals or groups affected by the conflict.

\section{To achieve employment-oriented, pro-poor and broad-based economic growth}

The government will play the lead role as well as a facilitator in creating opportunities for employment according to competence and skill of the new entrants to the labor market, while making the education system employment oriented. Policy reforms will be done to provide a working environment suitable for humans (workers) in both formal and informal sectors. Institutional arrangement will be made for providing skills and training in order to support the laborers and increase their productivity. While promoting the transfer of technology, a special consideration will be made that it is absorbable and matching to the condition of country and laborers. In this process, special emphasis will be given to big projects with high capacity to generate jobs and small participatory projects. Priority will be given to projects providing more employment to women, Dalits, Adibasi Janajatis, youths and 
the Madhesi communities immediately. For economic prosperity, strategies will be adopted to make the role of the private and cooperative sectors effective. For the alleviation of the existing poverty in the country, economic activities will be created and extended in order to raise the income of poor and helpless people by making them participatory. To meet this goal, the production and service sectors will be broadened and the self-employment sector will be promoted. Conducive environment will be created to run economic activities in a transparent, legitimized and safe environment. Strategies will be made to increase the role of private sector and cooperatives. Besides, the principle of public private partnership (PPP) will be adopted. The role of agriculture in economic growth will be enhanced. Inter linkages of this sector with the overall economy will be increased. Special programs will be run to enable the poor and the helpless to make them use their competence in order to increase their income. Non government organizations (NGOs) will be mobilized in the implementation of such programs.

\section{To promote good-governance and effective service delivery}

By strengthening the value of rule of law and the state machinery, creation of people's participation, transparency, accountability and a corruption-free environment, the access of all Nepalese including those excluded in economic and social service delivery will be increased. For this, the private sector and civil society (including NGOs and community organizations) will be accepted as partners in development. Necessary laws, policies and programs will be revised, formulated and implemented in addition to an emphasis on decentralization, institutional strengthening and capacity development.

\section{To increase investment in physical infrastructures}

In addition to putting special emphasis on reconstruction and development of social and physical infrastructures, new concepts will also be utilized. In the context of infrastructure, strategy will be adopted to construct mega, medium and small-scale projects with the help of identification and participation of local people. In addition, the roads that connect district headquarters, north-south corridors, rapid transit roads and road networks will be given special emphasis. Similarly, transport mediums like cable cars and ropeways that are significant from the perspective of tourism will be developed. Small and medium hydroelectric projects currently being constructed will be completed. Initiatives will also be taken to make mega hydroelectric projects started. Information and communication technology will be extensively expanded. In the case of infrastructures built through large investments, priority will be given to have their regular maintenance and quality improvement. 


\section{To give emphasis on social development}

Additional investments will be made on education, health, drinking water and sanitation and other social development activities to develop human resource and raise the living standard of the people. In order to make the services from these sectors effective, the responsibility of managing these services will gradually be transferred to the local bodies.

\section{To adopt an inclusive development process and carry out targeted programs}

Clear policies, institutional structures and programs will be implemented focusing on the excluded groups like Adibasi Janajatis, Dalits, Madhesi, women, and people with disability, extremely poor people and the people of remote geographical areas who are in this state due to prevailing discriminatory practices in society and weaknesses of state structures as such. While adopting the inclusive development process, participation of excluded groups in development investment and outcomes will be ensured and geographical, economic, social, gender solidarity and re-integration will be emphasized. This approach seeks to make special efforts in ending all forms of discriminations, promoting multiculturalism and guaranteeing peace peace. In order to ensure a basis for inclusive development macroeconomic, social and political development processes will gradually be engendered. Special programs for areas falling in the shadow of development programs like Karnali zone and regions along district/ international borders will be carried out. Programs will be launched to bring all types of excluded groups of people in the main stream of development. Even in the $21^{\text {st }}$ century, many individuals, groups and communities are still living a life that is unacceptable from a humanitarian point of view and from the perspectives of food security, health, education and other socio - economic conditions. Therefore, it has been thought that targeted programs will seek to end these conditions. Similarly, the people affected by conflict will be provided with relief and they will be rehabilitated and socially reintegrated.

\section{Conclusion}

Nepal has been trying to develop the country with the help of various development plans. So far, ten such plans have been completed. A huge infrastructure has been created. Nepal has a wider prospect of fostering development if it can minimize its challenges in the path of development on the one hand and intensify the people's participation on the other. However, its challenges are not always the same. Fro example, the major challenges at present are the presence of various types of conflicts, lack of economic confidence among domestic and foreign investors and lack of rule of law that has been causing the vandalism at all parts of the country. The country has opportunities also along with challenges. The opportunities like challenges also change time to time. Because of changing nature of opportunities and 
challenges, the development plans in Nepal have been found taking new turns in the course of time. So far, there has been found three major turns in the history of planned development of Nepal. First turn is associated with the fifth plan which had been made basically to focus the regional development and strengthen the involvement of government control in economic activities through the policy of party less Panchayat system. The second turn is found with the launch of eighth plan which was the first in itself after the restoration of democracy in Nepal It had focused the concept of privatization and economic liberalization. The third turn is in the form of three year interim plan that has been started after the downfall of kingship because of the historic people's movement in 2006. The turns have been analyzed basically on the basis of visions/ objectives and strategies of the plan on the one hand and the change in socio political situation in the country on the other. As far as the turns are concerned, these are good until and unless these produce positive economic results. The effects of turns are positive. Nevertheless, these are not that much effective as expected. Various factors are responsible for this. However, lack of accountability at various levels, absence of good governance and lack of people's participation to the desired extent are some of the major impediments on to the path of development plans.

\section{References}

National Planning Commission (NPC) 1975 Fifth Plan (1975-1980), Kathmandu: His Majesty's Government of Nepal (HMG/N).

NPC 1992 Eighth Plan (1992-1997), Kathmandu: HMG/ N, accessed through www.npc.gov.np/en/plansprograms/details.phs, March 25, 2009.

NPC 2007 Three Year Interim Plan (2007/08 - 2009/010), Kathmandu: Government of Nepal, accessed through www.npc.gov.np/en/plans-programs/details.phs, March 24, 2009. 